\title{
The age distribution of mortality due to influenza: pandemic and peri-pandemic
}

Tom Reichert ${ }^{1 *}$, Gerardo Chowell ${ }^{2,3}$ and Jonathan A McCullers ${ }^{4,5}$

\begin{abstract}
Background: Pandemic influenza is said to 'shift mortality' to younger age groups; but also to spare a subpopulation of the elderly population. Does one of these effects dominate? Might this have important ramifications?
\end{abstract}

Methods: We estimated age-specific excess mortality rates for all-years for which data were available in the 20th century for Australia, Canada, France, Japan, the UK, and the USA for people older than 44 years of age. We modeled variation with age, and standardized estimates to allow direct comparison across age groups and countries. Attack rate data for four pandemics were assembled.

Results: For nearly all seasons, an exponential model characterized mortality data extremely well. For seasons of emergence and a variable number of seasons following, however, a subpopulation above a threshold age invariably enjoyed reduced mortality. 'Immune escape', a stepwise increase in mortality among the oldest elderly, was observed a number of seasons after both the $\mathrm{A}(\mathrm{H} 2 \mathrm{~N} 2)$ and $\mathrm{A}(\mathrm{H} 3 \mathrm{~N} 2)$ pandemics. The number of seasons from emergence to escape varied by country. For the latter pandemic, mortality rates in four countries increased for younger age groups but only in the season following that of emergence. Adaptation to both emergent viruses was apparent as a progressive decrease in mortality rates, which, with two exceptions, was seen only in younger age groups. Pandemic attack rate variation with age was estimated to be similar across four pandemics with very different mortality impact.

Conclusions: In all influenza pandemics of the 20th century, emergent viruses resembled those that had circulated previously within the lifespan of then-living people. Such individuals were relatively immune to the emergent strain, but this immunity waned with mutation of the emergent virus. An immune subpopulation complicates and may invalidate vaccine trials. Pandemic influenza does not 'shift' mortality to younger age groups; rather, the mortality level is reset by the virulence of the emerging virus and is moderated by immunity of past experience. In this study, we found that after immune escape, older age groups showed no further mortality reduction, despite their being the principal target of conventional influenza vaccines. Vaccines incorporating variants of pandemic viruses seem to provide little benefit to those previously immune. If attack rates truly are similar across pandemics, it must be the case that immunity to the pandemic virus does not prevent infection, but only mitigates the consequences.

Keywords: Pandemic influenza, mortality due to influenza, recycling, pandemic attack rates, vaccination, protective immunity

\footnotetext{
* Correspondence: treichert@entropyresearch.org

'Entropy Research Institute, 345 S. Great Road, Lincoln, 01773, Massachusetts,

USA

Full list of author information is available at the end of the article
} 


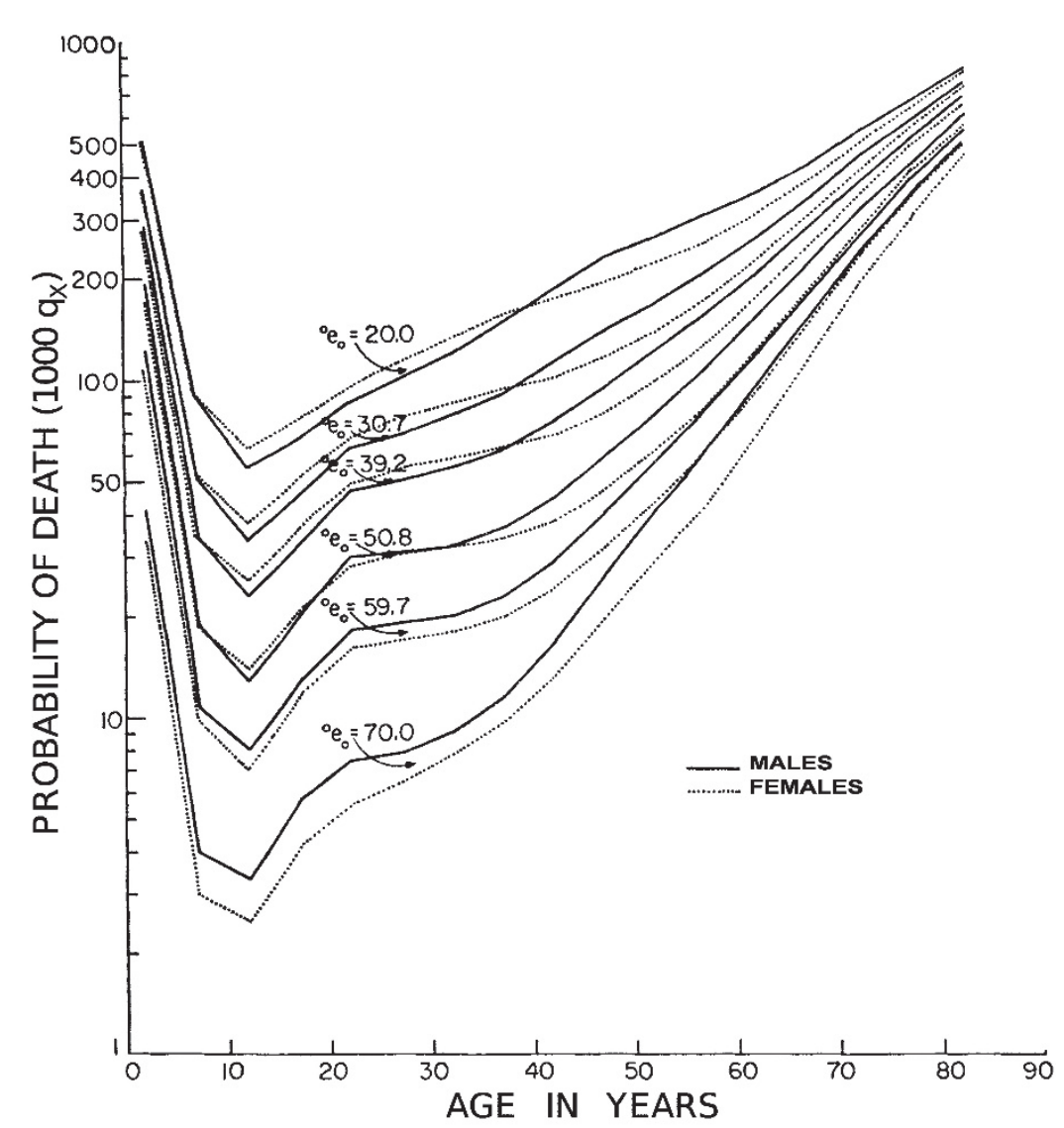

Figure 1 The probability of death versus age for human populations of successively longer median life expectancy (expressed as deaths per 1000 population). Source: Department of Social Affairs. Population Branch, Age and Sex Patterns of Mortality: Model Life Tables for Underdeveloped Countries. Population Studies, No. 22, New York, United Nations, 1955.

\section{Background}

Viewed against the backdrop of social evolution, the age distribution of the probability of death in human populations has a checkmark-like shape. The top curve in Figure 1 characterizes a society with life expectancy at birth of 20 years, about that for ancient Greece at the time of Pericles (448 to $404 \mathrm{BC}$ ). The lowest curve depicts the deathscape of a modern economically developed country, around 1950. The nested checkmark shapes derive from the fact that the mortality of infants and young children has always been greater than that of 8 - to 12-year-olds. Above this age range, mortality rates steadily increase. The most important additional feature is that the segment of each curve for ages of around 40 years and older approximates a straight line Because the ordinate of the graph is plotted on a logarithmic scale, a straight line indicates that human mortality increases about exponentially with age from young middle age onwards. Over the approximately 2,400 years between $425 \mathrm{BC}$ and $1950 \mathrm{AD}$, the death rate of 80 -year-olds decreased by approximately $50 \%$, or approximately $2 \%$ per century. Over the next 50 years, this death rate fell by an additional one-third in economically developed countries such as Canada (Figure 2). This is perhaps less remarkable than the fall of 70 to $80 \%$ in mortality for children from infancy to 12 years old over the same fifty years, but is evidence of true progress in human life extension.

Influenza-attributable or excess mortality has also been found to be exponential with age [1,2]. Figure 3 displays excess all-cause $(\mathrm{AC})$ mortality rates (estimated using the technique of this paper) for Canada, for a selected set of epidemic seasons in the era of circulation of $\mathrm{A}(\mathrm{H} 2 \mathrm{~N} 2)$ viruses in seasons dominated by $\mathrm{H} 2$ and $\mathrm{B}$ viruses. Trend lines are plotted for these seasons. It is clear that an exponential relationship exists, and that this relationship is quite similar for seasons of a type. Excess AC mortality rates in 85- to 90-year-olds are about 250 times greater than those for 45 to 50 -year-olds, whereas AC total mortality rates for 85 to 90 -year-olds are only about 75 times 


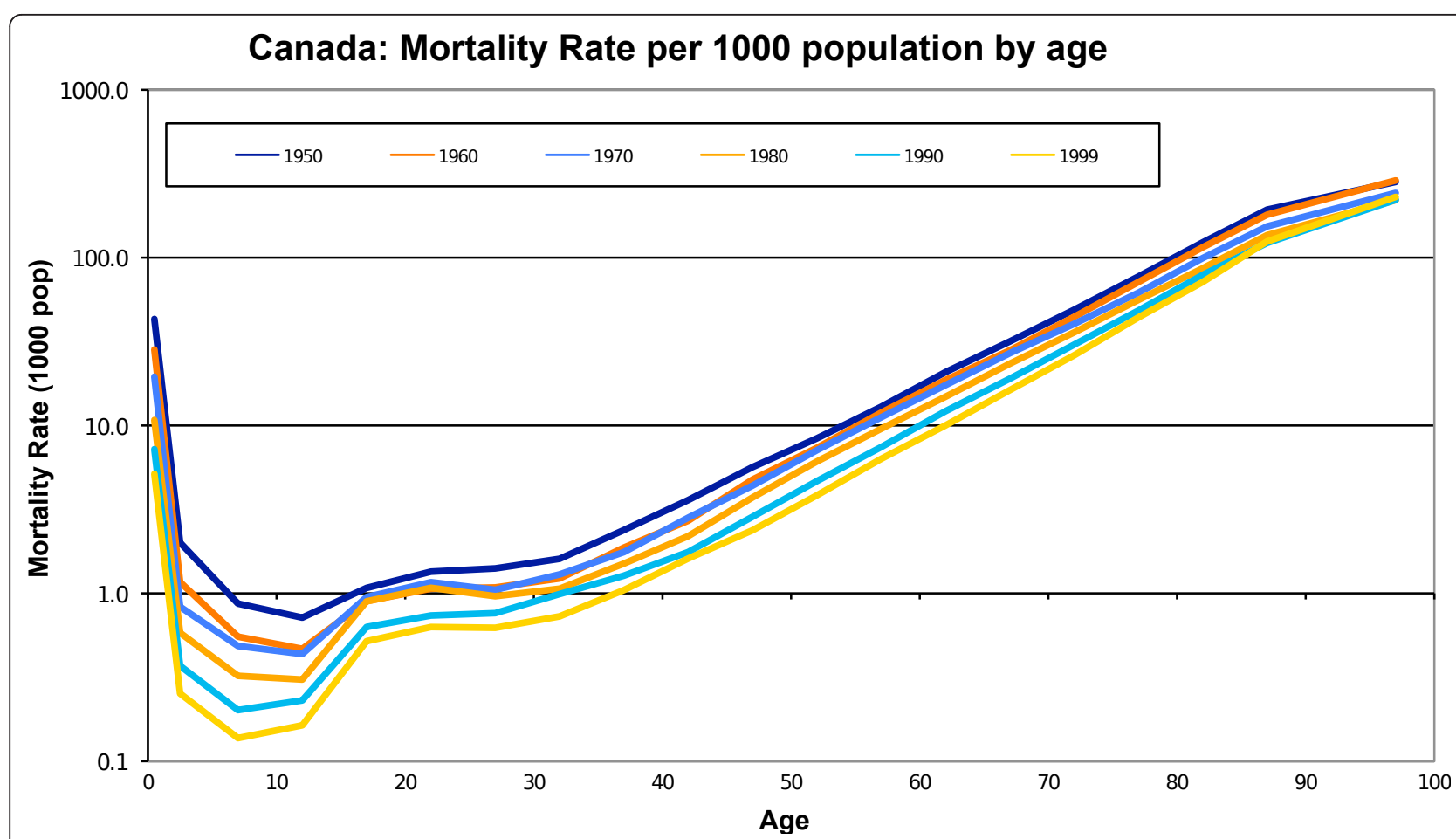

Figure 2 The evolution of observed age-specific all-cause mortality rates, scaled per 1000 population, in Canada over the second half of the 20th century. This evolution dovetails with the historical model of socioeconomic evolution.

larger than the rates for 45 - to 50 -year- olds. A characteristic of exponential processes is that a proportional change in the process occurs as a result of a fixed change in the driver of the process, here, age. The age increase associated with a doubling of the AC mortality rate was 7.15 years in Canada in 1999, while the doubling age increment for influenza-attributable mortality was 5.33 years. The exponential variation with age is, therefore, steeper for influenza-attributable mortality than for AC mortality. Seasonal influenza, as a mortal force, is of unusual consequence to the increasingly elderly population.

Two generalizations can be made from Figure 3. First, it is clear that excess mortality was higher in seasons in which mortality was dominated by influenza A-type

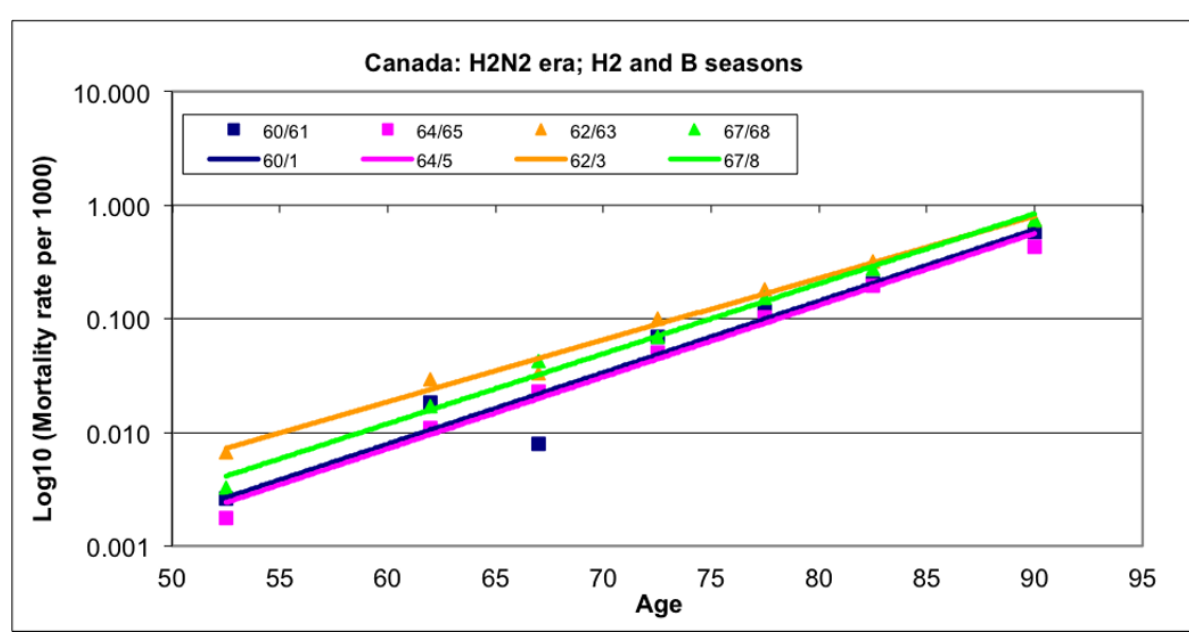

Figure $3 \mathrm{~A}$ semi-log plot of excess all-cause mortality variation with age for epidemic seasons during the era of circulation of influenza A(H2N2) viruses in Canada. The 1960/61 and 1964/5 seasons were dominated by B-type viruses, and the 1962/3 and 1967/8 seasons were dominated in mortality by H2N2 viruses. 
viruses. The pair of lines for $\mathrm{H} 2$ seasons lay wholly above the pair for B-type seasons, and the excess mortality rate was estimated to be about twice as great for the $\mathrm{H} 2$ seasons for each age group. The currently circulating subtypes of A-type influenza $(\mathrm{H} 1, \mathrm{H} 2$, and $\mathrm{H} 3$ ) have circulated in humans only since about the middle of the 19th century [3,4]. These viruses seem to have crossed the species barrier from the avian reservoir, possibly through an intermediate reservoir. A-type viruses mutate (at the nucleotide level) and evolve (at the amino acid level) relatively rapidly. By contrast, B-type influenza viruses have no known animal reservoir, and mutate and evolve at about half the rate of A-type viruses. They seem to be descended from a more ancient ancestor, and are correspondingly better adapted to humans. Possibly as a result, large changes with pandemic effect do not occur with B-type viruses and several lineages co-circulate [5].

Second, in inter-pandemic seasons dominated by Atype viruses, excess mortality generally declined with time, as the population adapted to viruses that had drifted modestly from those of earlier seasons. This occurred significantly more frequently in younger than in older age groups, with the result that the slopes of lines fit to points representing excess mortality in seasons dominated by the same type of virus tended to increase with time. In addition, periods of adaptation were necessarily interrupted by seasons in which mutations produced sufficiently large changes in antigenicity that the immunologic adaptations were abrogated in at least a subset of the population, and re-infection occurred, with corresponding rises in morbidity and excess mortality. The evolutionary dynamics of the A $(\mathrm{H} 1), \mathrm{A}(\mathrm{H} 2)$ and $\mathrm{A}(\mathrm{H} 3)$ viruses are different $[4,6]$, so the situation became much more complex after 1977 when $\mathrm{H} 1$ viruses re-emerged. These have co-circulated since that time along with $\mathrm{H} 3$ viruses. $\mathrm{H} 1$ viruses have diverse lineages and weaker antigenic drift, but this was not always the case [7]. H1 seasons are currently milder than H3 seasons, producing only slightly higher morbidity and mortality than seasons dominated by B-type viruses.

The largest numbers of deaths associated with influenza infection occurred in the years associated with the emergence of influenza viruses that were novel to most of the world's population, and also in the seasons immediately following this emergence [8]. The phrase 'pandemic age shift' is usually invoked to describe the observed increase in mortality among younger people in the first season of emergence of a novel influenza virus [9]. In the recent $2009 \mathrm{H} 1 \mathrm{~N} 1$ pandemic, both cases and deaths exhibited a clear predilection for younger age groups [10-13]. The mini-pandemic of 1977 produced substantial morbidity only in those under the age of 26
[14], and the infamous 'W-shaped' mortality curve of the 1918 pandemic reflected the unusually high mortality rate for 18- to 44-year-olds [15]. This raises several questions: Are younger immune systems more susceptible to and more severely affected by novel viruses? Or is mortality in pandemic seasons merely reset to the virulence level of the emerging virus, except among those immune by virtue of previous exposure, most of whom will be older? Is it possible to distinguish between these hypotheses using the data on pandemic mortality and that in the seasons immediately preceding and following emergence? Increasing our understanding of the epidemiological patterns of mortality during influenza pandemics compared with inter-pandemic periods in different parts of the world could lead to improved influenza control strategies.

In the present study, we generated, analyzed and integrated data on the mortality impact of influenza on the healthcare systems of six economically developed countries in and near the pandemics of the last fifty years of the 20th century.

\section{Methods}

The data for this study were obtained from the national health systems of Australia, Canada, France, Japan, the UK, and the USA [16]. All data available in the 20th century for AC and for pneumonia and influenza (P\&I) monthly mortality by age group were used. Wherever possible, 5-year age grouping was used, and all datasets end on 31 December 1999. AC mortality records began on 1 January 1950 for Canada, 1 January 1951 for Japan, 1 January 1959 for the USA and the UK, and 1 January 1968 for Australia and France. The P\&I datasets began on 1 January 1950 for Canada, 1 January 1959 for the USA and the UK, 1 January 1968 for Australia and France, and 1 January 1972 for Japan. The age-grouping practice was modified to allow the use of the data on some younger age groups in some of the countries with smaller populations. The Japanese data have not been used previously in any published analysis.

Influenza-attributable mortality rates (deaths per 1,000 of the relevant population or subpopulation) were estimated using a digital filter technique, which produces estimates very highly correlated with those of other methods [17]. This method was selected because it produces estimates that are strictly additive by age group, and are consistent in the sense that they are independent of which seasons are included in the analytical sample (For proofs of these assertions, see Additional file 1. Excel templates for digital filtering of monthly mortality data are available by request from the corresponding author). For each influenza season and country, we fitted a simple exponential model to the estimated excess mortality rate for each available age 
group [18]. AC excess mortality rates (ACxsMR), were modeled as ACxsMR $=k 1 \times \exp (k 2 \times$ age $)$, where $k 1$ and $k 2$ vary with time and country. The coefficients $k 1$ and $k 2$ were compared across epidemic seasons and countries by means of $95 \%$ confidence intervals (for tabulated results, see Additional file 2).

Mortality rate estimates for the youngest and oldest age groups differed by two orders of magnitude. To enable direct comparisons, we transformed the values of excess mortality for each age group and country using a standard technique, that of centering and scaling C\&S). (see Additional file 1 for a description, references, and a table of scaling parameters by country.) C\&S standardized excess mortality rates for every age group have a mean of zero and a standard deviation of one. The value associated with each season is the number of standard deviations by which that season's mortality rate differed from the mean for that age group/country. C\&S excess mortality rates for all age groups and countries can be plotted on the same graph. We used two graphical forms. For each country, we plotted these rates versus time in a 'rainbow' coloration for age groups, with the oldest age group in dashed black for easy identification (see Additional file 1, Figure S1). We also generated an 'area' form of each rainbow plot in which the area between a peak or trough and zero ordinate was filled with color.

Past pandemics have varied widely in their mortality rates. We sought insight into the two components of age-specific mortality rates attributable to influenza: the attack rate and the case fatality rate. We began with a recent discussion of attack rates for three pandemics [19]. Following the Preferred Reporting Items for Systematic Reviews and Meta-Analyses (PRISMA) statement guidelines (which aims to help authors improve the reporting of systematic reviews and meta-analyses) [20], we used the Web of Science search engine with the following keyword string for the title field: 'influenza' AND '1918', for articles relating to the 1918 pandemic; 'influenza' AND '1957' for articles relating to the 1957 pandemic; 'influenza' AND '1968' for articles relating to the 1968 pandemic; and 'influenza' AND '2009' for articles relating to the 2009 pandemic. We filtered out articles that did not include data on pandemic influenza incidence rates according to age groups. For additional relevant articles, we also examined articles cited in the references of the filtered articles.

\section{Results}

\section{The $\mathrm{A}(\mathrm{H} 2 \mathrm{~N} 2)$ pandemic}

We prepared semi-logarithmic plots of excess AC mortality rates for the seasons before and after the $\mathrm{A}(\mathrm{H} 2 \mathrm{~N} 2)$ pandemic in Canada and Japan, respectively (Figures 4A, $\mathrm{B})$, and fitted trend lines to the data for these seasons.
$R^{2}$ was greater than 0.99 for all fits to the Japanese data and for all seasons in Canada except the pandemic season $1957 / 8$ and the unusual $1961 / 2$ season. $P$-values for all $\mathrm{H} 2$ era seasons for Canada were less than $10^{-4}$ (mean $5 \times 10^{-7}$ ) and for Japan less than $5 \times 10^{-9}$ (mean $5 \times 10^{-}$ $\left.{ }^{10}\right)$, therefore an exponential relationship provided an excellent fit between $\mathrm{AC}$ excess mortality rate and age. The unusually high quality of the fit to the model is also testimony to the consistency of the estimation process, as the digital filter was applied to what should be more or less independent data series.

The excess mortality rate age distribution in the 1955/ $6 \mathrm{~A}(\mathrm{H} 1 \mathrm{~N} 1)$ pandemic season in Canada is shown in Figure $4 \mathrm{~A}$ (solid purple line). In the subsequent pandemic season, 1957/8, the ACxsMR trend line (red dashed line) had a markedly lower slope $(0.1026 \pm 0.0146$ versus $\left.0.127 ; R^{2}=0.985\right)$. The pandemic line appeared to rotate clockwise about the age of 80 years with respect to the trend of the 1955/6 season, demonstrating that mortality was lower for groups older than around 80 years, and higher for younger groups. In fact, pandemic mortality for the three highest age groups was lower in the pandemic season than at any time in the subsequent decade (Figure 4C). Relative to the pandemic season, mortality declined for the 1958/9 season (blue line) only for the youngest two age groups; and was sharply higher for all people aged over 65 years, being up to $40 \%$ higher for the oldest age group. $R^{2}$ was again greater than 0.99 , suggesting that the pure exponential relationship, disrupted in the pandemic, had been reasserted. Throughout the $\mathrm{H} 2$ era, the excess mortality rates for the oldest three age groups did not vary by more than $10 \%$ and did not show any systematic tendency, whereas younger age groups exhibited serial reductions of more than $40 \%$.

There were several differences in the $\mathrm{H} 2$ pandemic in Japan. First, the mortality in the preceding $\mathrm{H} 1$ season was generally greater than that in the pandemic. Exponential fits were excellent $\left(R^{2}>0.99\right)$ for every season. The 'axis of rotation' appeared to be about the age of 45 years, that is, mortality was lower in $1957 / 8$ than in $1956 / 7$ for every age group of 45 years and older, and the difference increased with age, from approximately $20 \%$ for the youngest of these age groups to approximately $50 \%$ for the oldest (Figure 4B). The 1958/9, $1962 / 3,1964 / 5$ and 1967/8 H2 seasons were a progression of increases in exponential slope, with each increment in the slope trend being statistically significant (for tables of coefficients and uncertainties, see Additional file 2: XS mortality rates fitted to an exponential model) The reductions in mortality for the youngest age groups were preserved in and after 1964/5, but mortality increased proportionately in all groups aged over 55 years, increasing by over $30 \%$ during the $1967 / 8$ season for the oldest elderly group. The $1961 / 2$ season was 

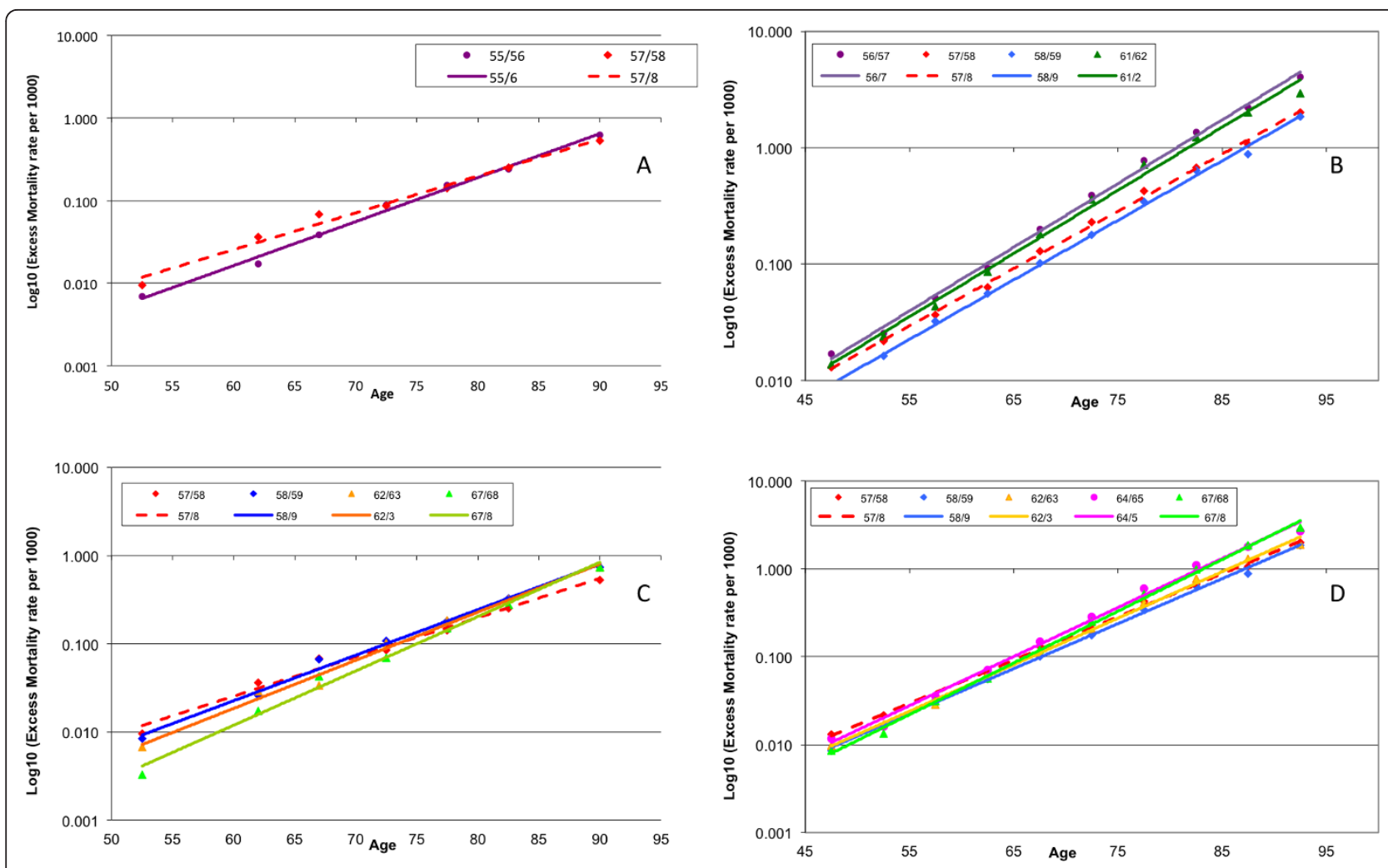

Figure $4 \mathrm{~A}$ semi-log plot of excess All-Cause excess mortality rate variation with age for epidemic seasons during the era of circulation of influenza $\mathbf{A}(\mathbf{H} 2 \mathrm{~N} 2)$ viruses in Canada (A) and Japan (B). The pandemic season appears as a dashed red line. Old elderly had their lowest mortality in that season. The most recent precedent season dominated by $\mathrm{H} 1$ viruses appears in purple. Mortality was generally decreased in the pandemic in Japan. The different time courses of immune escape in these countries are shown in Canada (C) and Japan (D)

divergent. We have no information on the dominant virus in circulation for that season in Japan, and so can only note that the age variation is strikingly similar to that in the last H1-dominated season (1956/7), and dissimilar to all other $\mathrm{H} 2$ seasons (Figure $4 \mathrm{~B}$ ).

The pandemic reduction in mortality in the old elderly thus lasted only one season in Canada, but extended over seven seasons in Japan. The age variation in excess mortality rate showed no tendency to deviate from a highly significant exponential relationship in Japan in any season, and the time trend to higher slope (that is, of increasing relative mortality risk for the increasingly elderly) was monotonic (Figure 4D).

\section{The $A(H 3 N 2)$ pandemic in Canada and the USA}

The emergence of $\mathrm{A}(\mathrm{H} 3 \mathrm{~N} 2)$ viruses was very similar in Canada and the USA, but very different in the rest of the world. In the USA, (largest $P$-value, $2 \times 10^{-7}$, mean $7 \times 10^{-8}$ ) mortality among elderly people was relatively high during the most recent $\mathrm{H} 2$ season in the USA, in 1967/8 (Figure 5F, chartreuse line). The pandemic season trend was rotated clockwise from that for the preceding season (dark-green dashed line). The slope change was 0.03 units, and the uncertainty in each estimate was 0.006 units. The $1969 / 70$ seasonal trend was precisely parallel to that for $1968 / 9$, but at two-thirds of the amplitude of the earlier season. The mortality in the next H3 season, 1971/2, was indistinguishable from that of 1969/70; however, in $1975 / 6$, there was a statistically significant increase in slope, a counterclockwise rotation, with younger age groups enjoying a reduction in mortality of about one-third, while the oldest age groups had a $50 \%$ increase in mortality rates.

For the emergence of $\mathrm{H} 3$ viruses in Canada, the $P$ values for the trends displayed were strikingly higher (mean $4 \times 10^{-4}$ ), with the highest value, $1.8 \times 10^{-3}$, seen for the pandemic season 1968/9 (Figure 5b). Although this highest $P$-value is still very small, we believe that the relatively low $R^{2}$ value of 0.88 for this particular fit should be taken as corroboration of a visually apparent departure from exponentiality. The trend lines for 1969/ 70 and 1971/2 were again indistinguishable. The mortality reduction for younger age groups and the 50\% increase in the mortality for the oldest elderly groups (those aged over 80 years) in 1975/6 were also similar to those in the USA. 

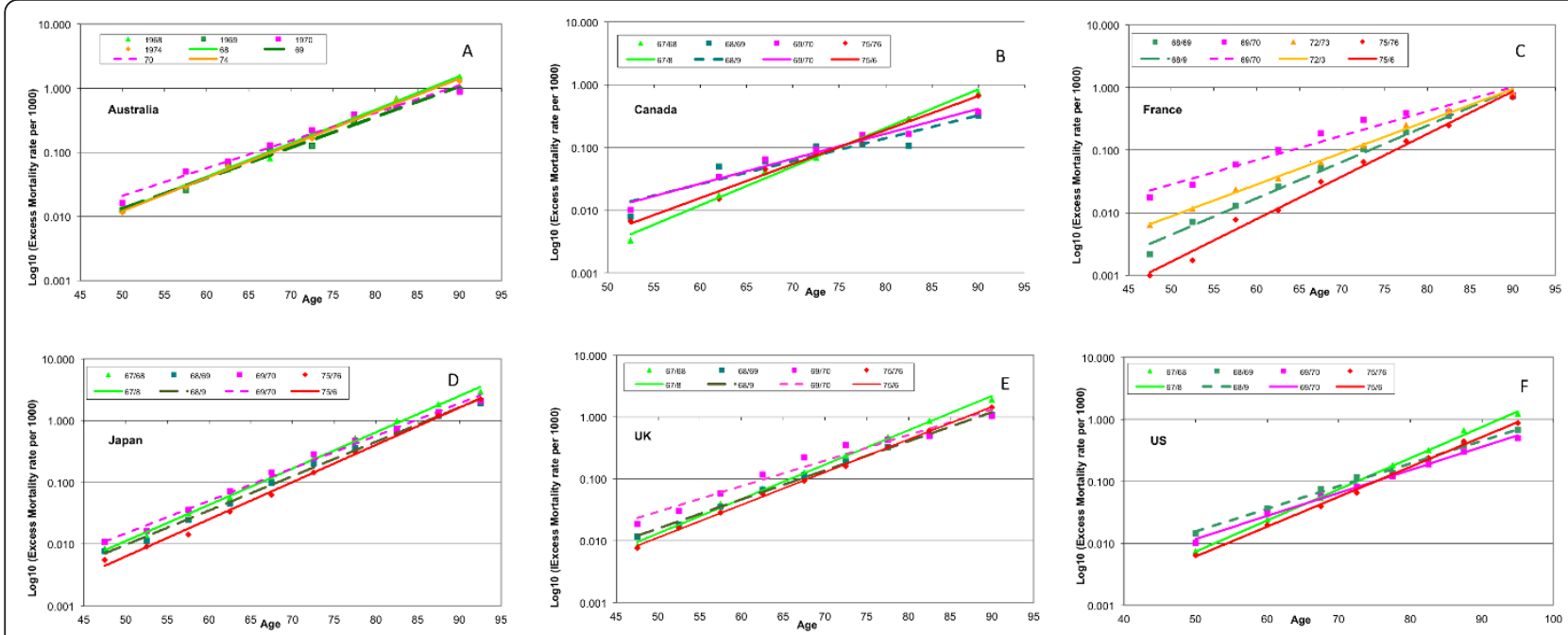

Figure $5 \mathrm{~A}$ semi-log plot of excess all-cause mortality rate variation with age for epidemic seasons before, including and immediately after the emergence of $A(H 3 N 2)$ viruses in (A) Australia, (B) Canada, (C) France, (D) Japan, the (E)UK and the (F) US, in alphabetical order. The pandemic season is shown as a dashed dark-green line. For countries other than the USA and Canada, the season of emergence was one of low mortality, while the second season was severe (short-dashed fuchsia line). The oldest elderly population over the age of 78 years had reduced mortality in the severe pandemic season, everywhere. This mortality reduction was lost abruptly in the 1975/6 season, except in France.

\section{The $A(H 3 N 2)$ pandemic elsewhere than Canada and the USA}

Relative to the most recent season dominated by $\mathrm{H} 2$ viruses (chartreuse trend lines), mortality declined in Australia, Japan, and the UK (Figures 5A, D, E) in the pandemic season of emergence (long-dashed dark-green trend lines for 1969, 1968/9 and 1968/9, respectively), but only in the oldest elderly people (aged over 78 years, approximately). The $P$-values for these fits dropped by 10-fold, 25-fold and 2-fold, respectively. For the second season after emergence (1970, 1969/70, 1969/70), the trend line (fuchsia) slope decreased by an amount about equal to the uncertainty in the previous season's estimate, and the $P$-value for the fits dropped another 40 -fold, 10 -fold, and 10,000-fold $\left(10^{-10}\right.$ to $10^{-6}$. This is the statistical result of an increase in mortality rates for all ages younger than 75 years, and no change at all for older age groups. Younger age groups experienced progressive reductions in mortality in intervening H3-dominated seasons (1972, 1973/4, 1972/3), but the older age groups had no change until later seasons (1974, 1975/6, 1975/6, when they experienced a 35 to $40 \%$ increase in mortality rates. Younger age groups alone exhibited further adaptation (mortality reductions) in 1976 in Australia but not in the other two countries.

The H3 pandemic in France was unusual in a different way (Figure 5C). Unfortunately, age-specific mortality data were not available for the most recent $\mathrm{H} 2$-dominated season. In Australia, Japan and the UK, the overall increase in mortality from the first to the second pandemic season for age groups younger than 75 years was
50 to $70 \%$, whereas in France this increase was four-fold (400\%; compare dashed dark-green with the fuchsia trend lines), from about half the mortality levels of the three countries listed above to about the level of the highest of these (the UK). There was sequential and proportionate adaptation of younger age groups through the 1975/6 season, but no apparent change in the mortality rates for the oldest age group.

These data are displayed in a different manner for further clarity (Figure 6A-F). Each panel shows the C\&S excess AC mortality for one of the six countries using an area coloration scheme, with a dashed black line marking the oldest age group. All peaks after 1967/8 occurred in seasons dominated by $\mathrm{H} 3$ viruses. In the USA (Figure 6F), the dashed line traced the top or neartop of every peak except for those for the pandemic of $1968 / 9$ and the following seasonal epidemics, which were dominated by H3 viruses, until the 1975/6 season. The dashed line also outlined nearly all troughs. Beginning in the pandemic season and extending until the 1975/6 season, C\&S excess AC mortality for the progressively older population was correspondingly lower, with the oldest age group experiencing mortality below the mean (less than zero $C \& S$ ). The reduced mortality risk was most dramatically lowered in the progression for the age group aged 75 to 79 years, and we infer that all people of age above the mid-point of that age group (the threshold age) were protected from the pandemic virus and its immediate descendant viruses. A drift variant emerged in 1975/6, the 'Victoria' variant, which abrogated the immunologic protection of these above- 


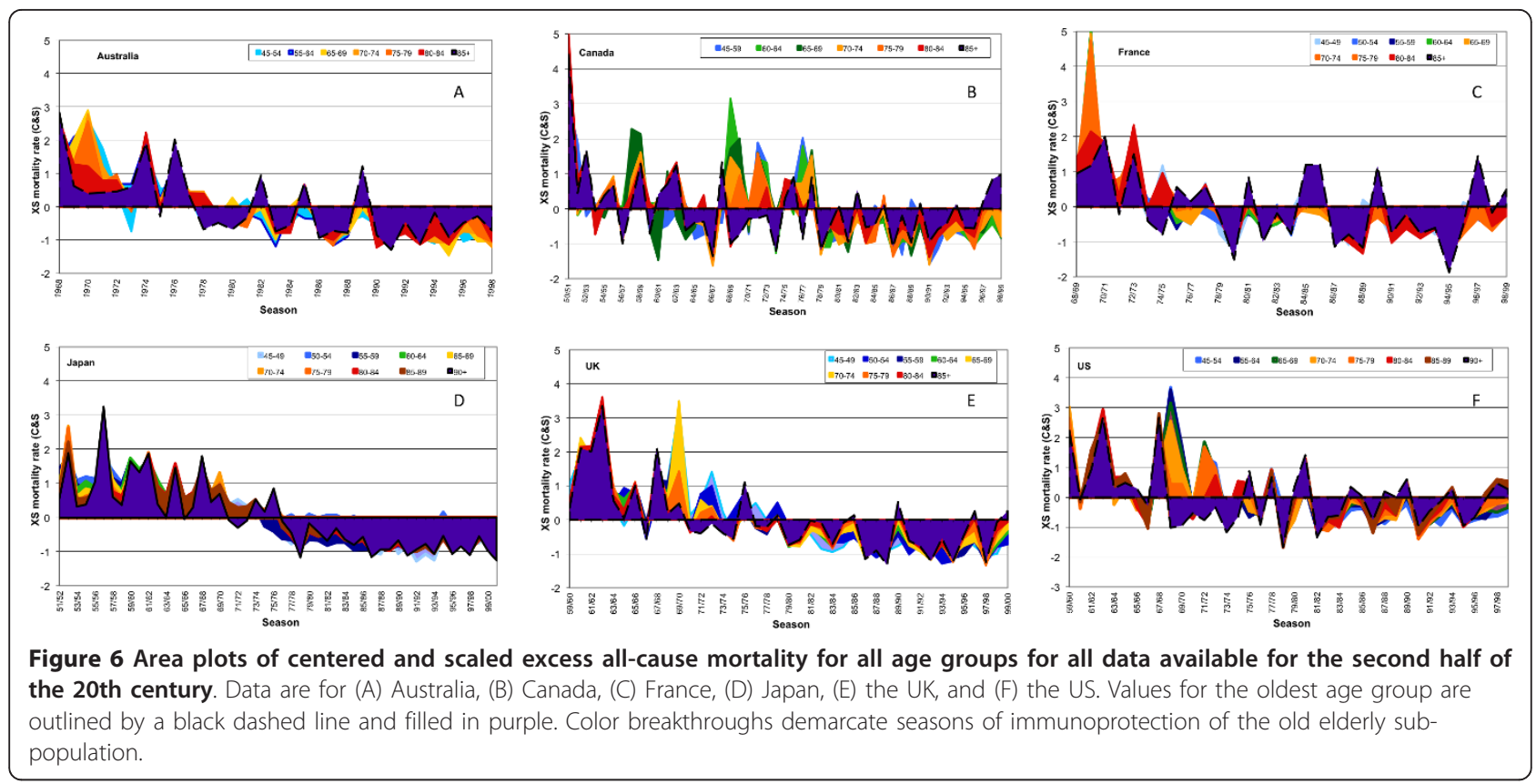

threshold elderly people, reinstituting the higher risk of mortality for influenza to the very elderly person. The period $1968 / 9$ to $1974 / 5$ was the only interval in the 40 year data span in which the oldest elderly population was not at the highest relative level of mortality risk.

The impact of influenza from 1976 to the end of the 20th century

In four countries (Canada, France, the UK, and the USA), there was no change in mortality rates for the oldest three age groups after 1976 (Figure 7B, C, E, F); the lavender to purple-hued trend lines rose to the same point at oldest age for the relevant countries). In Canada, France, and the UK, the trend lines for H3dominated seasons after 1976 were not statistically significantly different in slope or magnitude from that for the 1975/6 season. In France, there was no apparent trend toward changing slope or magnitude. For Canada and the UK, this possible trend did not reach statistical significance. For the USA, the trend towards progressive adaptation of younger age groups, reflected in increasing slope and decreasing magnitude for seasons after 1975/6 (Figure 7F), became statistically significantly different from $1975 / 6$ only in $1997 / 8$.
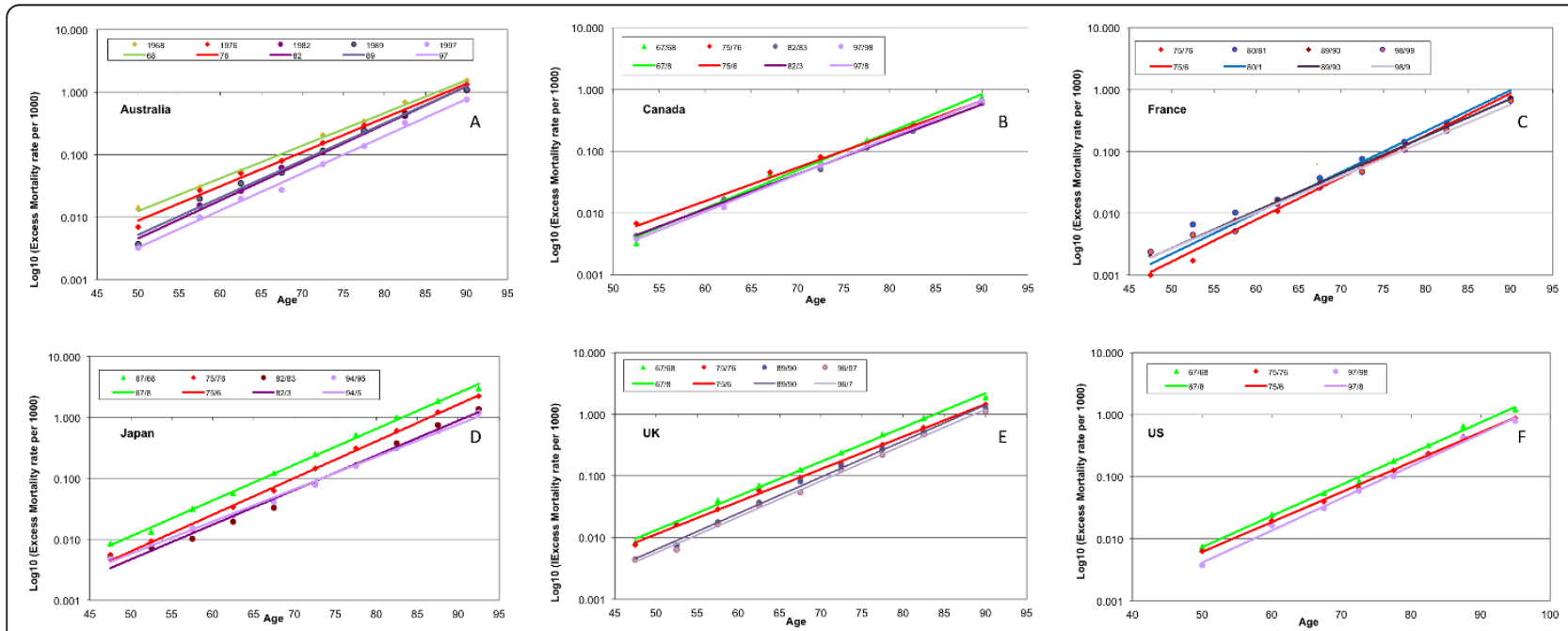

Figure $7 \mathrm{~A}$ semi-log plot of excess all-cause mortality rate variation with age for H3-dominated seasons of immune escape and later. Six countries ((A) Australia, (B) Canada, (C) France, (D) Japan, (E) the UK, and (F) the USA) are shown, in alphabetical order. 
In Australia (Figure 7A), the trend lines for the three most severe H3 seasons after 1976 (1982, 1989, and 1997) were significantly different from 1976 in both slope (steeper) and magnitude (lower); however, they were not significantly different from one another. In this case, then, there was a reduction in mortality in all age groups, slightly greater in younger age groups.

In Japan (Figure 7D), the slopes for later H3 seasons (1982/3 and $1994 / 5$ or $1997 / 8)$ were significantly different from one another and from the 1975/6 season, but the time trend was toward lower slope, suggesting mortality reduction favoring the older elderly population. Overall, there was a four-fold reduction in the mortality rates for all age groups, about equally between 1975/6 and $1997 / 8$.

\section{Do pandemic attack rate data provide additional insight into immunoprotection?}

The entire human population is potentially susceptible to pandemic viruses except for those individuals who are relatively immune as a result of previous exposure to similar viruses in the remote past. If such viruses are so highly transmissible that the general characteristics of social contact among individuals are sufficient to largely determine the age distribution of cases [21] (for example, that each age group has primary social contact with itself), then it is not unreasonable for there to be significant similarities in attack rates across pandemics. The distribution of cases by age in pandemic seasons was well characterized for the $1918 / 9 \mathrm{~A}(\mathrm{H} 1 \mathrm{~N} 1)$ pandemic season in the USA [22] and the 2009 pandemic in the UK [23], but only sparsely for the H2 and H3 pandemics, for which detailed data were available only for a single site for families with school-age children [24] plus a single nursing-home population for the $\mathrm{H} 3$ pandemic [25] (Figure 8). There is remarkably little scatter in the data for $1918 / 9,1957 / 8$, the nursing-home population from 1968/9, and the 2009 influenza pandemics. However, the data of Davis et al. [24] for 1968/9 were essentially flat versus age, and were different not only from those of all other pandemics, but also from the data on older people in a more isolated environment in the same pandemic. Ignoring data for children aged younger than 7 years (for whom the age trend is likely to be positive), the data are fit well by a linear model of negative slope. $R^{2}$ for the fit to all the data except the 1968 data of Davis et al. is 0.81 (approximately $\mathrm{P}=10^{-12}$ ). The data presently do not permit a definitive statement. A pan-pandemic trend, if validated, would greatly simplify future modeling studies. Further study would be valuable because: 1) preparations for every pandemic should then be similar, focused on interrupting contagion, and concentrated on younger age groups; and 2) because pandemic viruses then differ only in their mortality impact (case fatality rates), it becomes interesting to ask whether these differences are qualitative or quantitative.

\section{Discussion}

In this study, we characterized the data for eight pandemic seasons in six economically developed countries: two countries for the $A(H 2 N 2)$ pandemic and all six for the $\mathrm{A}(\mathrm{H} 3 \mathrm{~N} 2)$ pandemic. In all these, an older subpopulation of the elderly population experienced reduced mortality in the year of emergence. In countries other than Canada and the USA, mortality was unchanged from the preceding $\mathrm{H} 2$ season for all younger age groups in the season of emergence of the H3 viruses, but strongly increased in the second season after emergence, Mortality remained unchanged, however, in the oldest elderly population. It is clear, therefore, that the primary element affecting overall mortality in pandemic emergence is the existence of a relatively immune subpopulation aged above a threshold age. As a result, pandemic mortality was relatively greater in younger age groups in the first season, and absolutely increased over the $\mathrm{H} 2$ baseline in the second season, except in Canada and the USA, where these effects could not be separated. We therefore suggest that there is no pandemic 'shift' in mortality to younger age groups, merely a virulence-directed change in overall mortality, modified from a purely exponential variation with age by the relative immunity of persons above a threshold age who had experienced infection in the past with a virus similar to the emerging virus. This mortality sparing was eventually lost in every country. In Australia, Canada (in both the $\mathrm{H} 2$ and $\mathrm{H} 3$ pandemics), Japan (in the $\mathrm{H} 3$ pandemic), the UK, and the USA, mortality increased sharply in the spared age groups in a single season. We call this step up in mortality in previously protected subpopulations 'immune escape,' in epidemiological analogy to the term that was first used to characterize the escape of spontaneously metastasizing tumors from immunological control [26], and was later applied to a discussion of impaired immunological response of T-cells in infectious disease [27]. In France, younger age groups progressively gained mortality reductions until 1975/6, after which time there were no additional gains for any age group. In the $\mathrm{H} 2$ pandemic in Japan, all age groups had reduced mortality in the pandemic season, but the protection was proportionately larger with age. This protection was lost sequentially, season by $\mathrm{H} 2$ season.

\section{The $\mathrm{A}(\mathrm{H} 2 \mathrm{~N} 2)$ pandemic}

The only two countries for which age-specific mortality data were available for both the $\mathrm{H} 3$ and $\mathrm{H} 2$ pandemics were Canada and Japan. In both countries, pre-pandemic epidemic seasons were well characterized by 


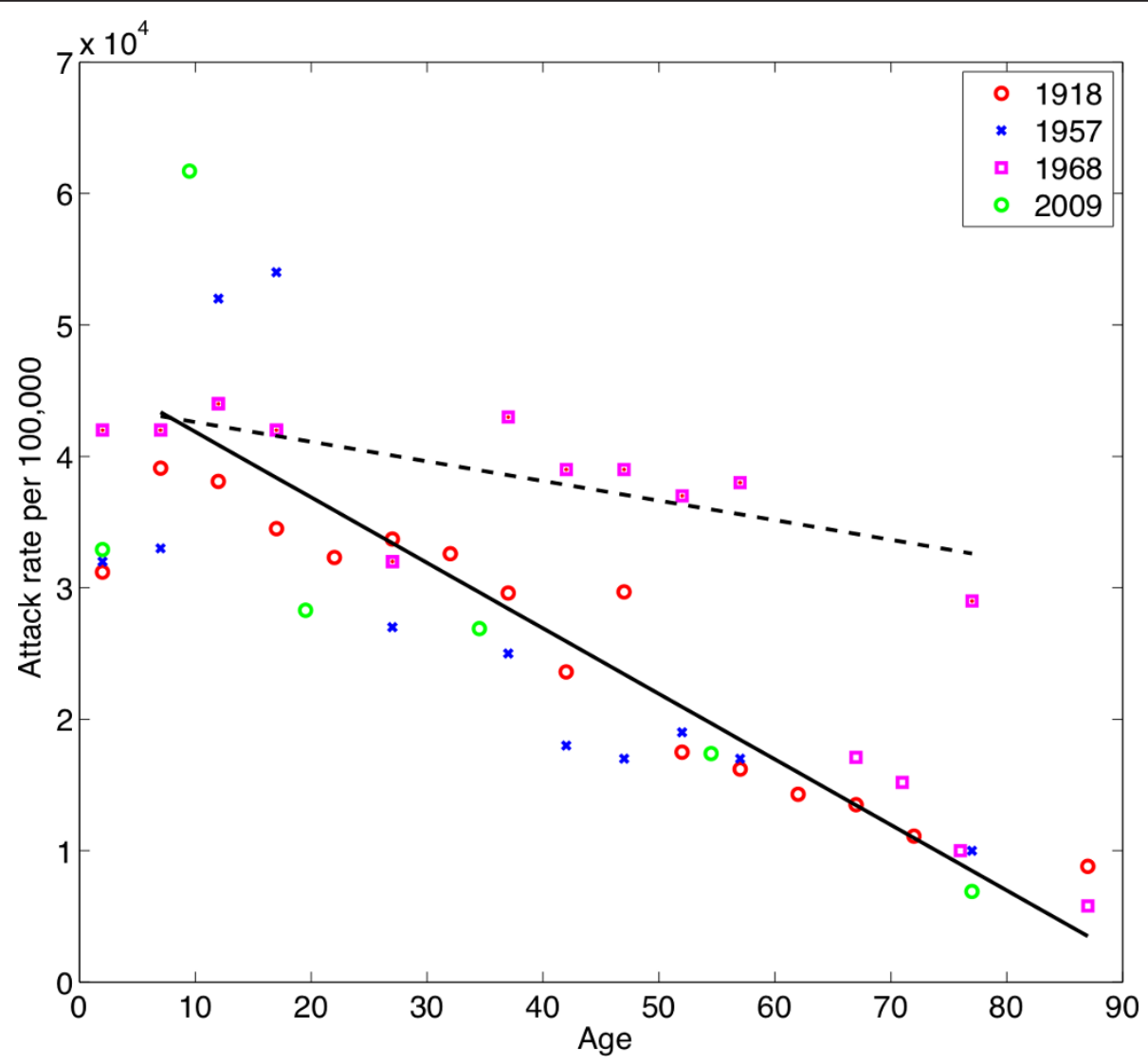

Figure 8 An estimate of age-specific attack rates hypothetically applicable to all pandemic seasons. The data displayed are for the pandemics of 1918/9, 1957/8, 1968/9. and 2009/10. The data for 1968/9 come from two studies. The data from Davis et al. were fit separately. All other data are fit well by a linear trend that decreased linearly with age.

highly statistically significant, log-linear, positive slope trends with increasing age for excess AC mortality (Figure $4 \mathrm{~A}, \mathrm{~B})$. The pandemic seasons were characterized by overall levels of mortality that were discontinuous with the trends for previous seasonal epidemic years. The pandemic mortality rates were higher or lower than those for previous years, depending on the relative virulence of the emerging virus. In Japan, the $\mathrm{H} 1$ season immediately prior to the $\mathrm{H} 2$ pandemic was particularly severe. Accordingly, in the pandemic year, every age group experienced a decline in mortality, and this difference increased monotonically with age. Subsequently, post-pandemic mortality rates moved monotonically back toward the trend in pre-pandemic seasons, while maintaining a highly significant exponential relationship

\section{The $\mathrm{A}(\mathrm{H} 3 \mathrm{~N} 2)$ pandemic}

The $\mathrm{A}(\mathrm{H} 3 \mathrm{~N} 2)$ pandemic was remarkable in that the year of emergence was a season of reduced mortality everywhere in the world except in Canada and the USA, while the second season was severe everywhere. The first season of circulation of $\mathrm{A}(\mathrm{H} 3 \mathrm{~N} 2)$ viruses produced severe mortality in Canada and in the USA, taken in its entirety, but mortality was relatively low, not only in most other countries, but also in the Pacific provinces of Canada, the central and mountain regions of the USA, and in Mexico [28]. The basis for this variability is controversial $[29,30]$. In Japan and the UK, there was a one-year delay (Figure 5D, E), after which the situation played out in essentially the same way as in northern North America. Similarly, in Australia, the first pandemic season was 1969 , but severe mortality did not occur until 1970, followed by immune escape in 1974 (Figure 5a). In France (Figure 5c), the first H3 season was also relatively mild; however, the $1969 / 70$ season was extraordinarily severe. Immune escape apparently did not occur in France; rather, there were progressive mortality reductions in younger age groups, with no change in the oldest elderly mortality rates even to the end of the century. This implies that the circulation of $\mathrm{H} 3$ viruses was different in France from that in the neighboring UK, possibly in the 1970s, but certainly during the late 19th century when H3-like viruses circulated. 
The initial reassortment event that gave rise to the 1968 pandemic $\mathrm{A}(\mathrm{H} 3 \mathrm{~N} 2)$ strain apparently resulted in a mismatch between the avian $\mathrm{H} 3$ hemagluttinin and the humanized N2 neuraminidase. The $\mathrm{H} 3$ viruses that circulated in the late 1800s had equine-like versions of N2 $[31,32]$. However, the differences in severity in the first H3-dominated seasons in locations other than Canada and the USA probably reflect not only different rates of resolution of functional mismatch of these two gene products [33], but also a sifting of the large number of genomic combinations that were identified in circulation beginning in 1969, owing to an intermixing of the two clades that had emerged in the most recent years of circulation of $\mathrm{H} 2$ viruses [34]. The lack of a single course of evolution is especially evident in the schema for the $P B 2$ and $P A$ genes [4]. In other words, it is the refinement in the field of the performance of a large number of permutations that were generated as $\mathrm{H} 3$ replaced $\mathrm{H} 2$ in many recombination events, rather than a single genomic substitution, that best explains the sputtering entry of $\mathrm{H} 3$ viruses in most parts of the world.

\section{Comparison of the $\mathrm{H} 2$ and $\mathrm{H} 3$ pandemics}

The mortality patterns of the $\mathrm{H} 2$ and $\mathrm{H} 3$ pandemics were similar in Canada, with steps up in mortality and a sharp demarcation in age above which immunoprotection was evident. The post-pandemic escape from immunoprotection was also a step in time. The greater mortality attributed to the earlier pandemic was due to the more complete immunoprotection in the $\mathrm{H} 3$ pandemic [35]. The pandemic mortality reduction in the $\mathrm{H} 2$ pandemic in Japan increased directly with age. The different levels of immunoprotection, recycling ages, and pattern of immune escape in Canada and Japan suggest that there were significant differences between the $\mathrm{H} 2$ viruses of the 19th and 20th centuries [36], and that the circulation of these only somewhat similar viruses in the late 1800 s produced local variants that were also very different. It may be relevant that Japan was somewhat isolated before its opening to outsiders in the late $1800 \mathrm{~s}$.

\section{Conclusions}

Pandemics do not 'shift' mortality to younger ages

From this study, it is evident that pandemics do not 'shift' mortality to younger ages. Rather, the entire mortality level is simply reset to the virulence level of the emergent virus. This reset is accompanied by immunoprotection in older age groups, which is determined by their level of previous experience with viruses similar to that emerging.

All known pandemics have involved 'recycled' viruses It is well accepted that older persons (aged over 45 to 55 years of age) were spared in the $1918 \mathrm{~A}(\mathrm{H} 1 \mathrm{~N} 1)$ pandemic $[37,38]$, although as reported above for $\mathrm{H} 2$ viruses, recent data from central Mexico and Colombia suggest geographic differences in pre-existing immunity to these viruses $[39,40]$. We and others have shown that older people (aged over 62 years), were spared in the 2009 H1N1 pandemic [10] and individuals older than 26 years were reported to be spared in the mini-pandemic re-emergence of H1N1 viruses in 1977/8 [14]. Therefore, it appears that in all five events over the past 100 years in which an influenza virus emerged with pandemic effect, a significant proportion of then-living individuals aged above a particular threshold age were immunologically protected from the emergent virus. Such viruses are said to be 'recycled' [25]. Our data are consistent with sero-archeology studies in which antibodies to pandemic viruses have been identified in agecohort sera drawn before the H3 pandemic [41]. Unfortunately, the sero-archeology data on past circulation of $\mathrm{H} 2$ viruses is inconsistent. As we noted above, the 2009 pandemic virus was most similar to $\mathrm{H} 1$ viruses that circulated before 1947. Therefore, the concept of recycling must be broadened to include not only pandemic viruses, but also antigenically significant variants of emergent viruses. Lessler et al. [42] have recently shown that sero-archeology curves (plots of antibody levels in age cohorts versus the cohort age) of pandemic viruses and their variants are essentially indistinguishable, except for a displacement in time to the date of emergence of the variant.

\section{Immunoprotection from recycled viruses is a cardinal attribute of pandemics}

It is clear that immunoprotection from recycled viruses is a cardinal attribute of pandemics, and this conclusion leads logically to several corollaries, as follows.

\section{Immunoprotection should direct pandemic planning}

Vaccines will not be required for protection for those aged above the age of recycling (Above the Age of Recycling Persons; AARPs), for both pandemic seasons and epidemic seasons dominated thereafter by variants of the pandemic virus, until immune escape occurs. Therefore, this otherwise high-risk population segment, easily defined in advance for any candidate pandemic virus, can be provisionally removed from pandemic vaccine planning. As there is a consensus among those modeling vaccine performance that deploying vaccine first to children and working adults should provide more effective protection, and as global vaccine production is inadequate, this should improve the level of effective coverage. Of course, if an AARP should become infected with pandemic influenza, the high $a$ priori expected case fatality rate implies that antiviral resources should be made immediately available to them. 


\section{Immunoprotection does not prevent infection, only the consequences of infection}

We have remarked that the data on variation in pandemic attack rate with age appears surprisingly similar across all four pandemics, suggesting a linear decline with age. We found similar threshold ages above which immunoprotection from mortality was present in both the $\mathrm{H} 2$ and $\mathrm{H} 3$ pandemics. However, these thresholds are both higher than the age threshold for protection in the $2009 \mathrm{H} 1$ pandemic (approximately 62 years), the $1918 \mathrm{H} 1$ pandemic (45 to 55 years) and the 1977 minipandemic (approximately 26 years). If a universal attack rate for pandemics is a viable hypothesis, then this must mean that immunoprotection from mortality does not influence the infection rate, but only the severity of its consequences. It could even be argued that a universal pandemic attack rate is the epidemiologic correlate of the well-known immunologic observation that the control of the spread of virus infections lies in the rapid response of memory $\mathrm{B}$ - and $\mathrm{T}$-cells, but that circulating levels of antibodies and armed T-cells are insufficient to prevent viral entry entirely $[43,44]$.

\section{Immunoprotection must be explicitly considered in vaccine trials}

Trials of vaccines and studies that analyze the effects of influenza vaccination should either exclude or analyze as positive controls the already immune AARP population segment, both for the pandemic season and for the following seasons until immune escape occurs. After immune escape occurs, and until a future time when descendant viruses have mutated so completely that infection no longer stimulates the pattern of response conditioned by exposure at an early age to similar viruses (that is, original antigenic sin, OAS [45]), AARPs will falsely appear to be vaccine failures. The degree of vaccine effectiveness will necessarily be very low, possibly even negative in the first season of immune escape, and will rise as the evolutionary distance from the pandemic virus increases [46]. Unfortunately, little is known about the restoration to immunological grace after OAS.

Immunoprotection may be a key to pandemic survival for organizations too

If pandemic attack rates are indeed universally low for the pre-immune elderly person, employers should consider prospectively recruiting AARPs for positions crucial to the missions of their enterprises. AARPs experience seasons of emergence as no more severe than seasonal influenza epidemics. Absenteeism among working-age populations in severe pandemics could reach levels of $50 \%$ or more. Assembly line-like activities can usually tolerate no more than $20 \%$ absenteeism. It is true that the mortality rate of AARPs is likely to be absolutely higher than that of the younger population in pandemics; but it will be relatively lower, and the attack rate for AARP's will be absolutely lower.

Immune escape may be accompanied by substantial increases in mortality and morbidity

Our data show that immune escape may be immediate or delayed for several seasons. This may also be seen in reports analyzing the 1918 pandemic, from which immune escape, as an increase in excess mortality among the elderly population, did not occur until 1926 $[47,48]$. There is some genomic insight into the evolution of H3 strains, A series of amino acid changes occurred between 1971 and 1975 [49]. Coincident with the loss of immunoprotection in AARPs in 1975/6, the variant A/Victoria/3/75 appeared, in which two glycosylation sites were added onto the globular head of HA, at positions on HA 81 and 126, while losing a site at position 63. These nascent glycosylation sites were located within antigenic sites $E$ and $A$, respectively, and the site that was lost at position 63 was also within antigenic site E. We hypothesize that this change in glycosylation, particularly the addition of the position 126 site within antigenic site A, abrogated the immunoprotection of the OAS response in AARPs, allowing re-infection [50]. Lessler et al. [42] found that H3/Victoria/3/75 was the least antigenic of the nine $\mathrm{H} 3$ viruses in their study, all of which circulated sequentially. This is surprising given the large excess mortality rate estimated for the 1975/6 season. Two studies have reported that vaccination of humans with inactivated viruses does not produce an OAS effect, that is, induced antibody shows a higher affinity to a previously encountered influenza virus strain than to the virus strain present in the vaccine $[51,52]$. However, it may be of significance that the OAS strain in the first of these studies was Victoria/3/75. Kim et al. [53] found that sequential administration of inactivated virus vaccine resulted in a higher viral load and defective clearance in mice on challenge with the second virus in the sequence, and they also found (again in mice) a large OAS effect on serial natural infection, independent of order. Possibly more importantly, Zhou and Deems [54] have argued that, in dengue (for which there are four known viral subtypes), OAS is augmented when infection with a highly antigenic subtype is followed by infection with a cross-reactive subtype that is significantly sub-dominant to the first, and is muted in the reverse situation (first infection by a sub-dominant subtype followed by second infection with a more dominant subtype). This would appear to be the situation that existed in 1975/6 with the emergence of the Victoria/3/75 variant. Zhou and Deems provide a mathematical model of $\mathrm{T}$-cell response that seems to account generally for the observed response. If an analogy may indeed be extended to influenza, managing the $\mathrm{T}$-cell 
response is an important feature currently lacking in influenza vaccines that needs to be addressed if immune escape is to be mitigated.

If an emergent virus is, like novel H1N1 of 2009, a virus recycled from a point well along in its adaptation to the human species, antigenic sites will have drifted in both amino acid sequence and in the generation of glycosylation sites. Because the 2009 virus is relatively nonvirulent, the analogy with dengue would suggest that the potential for an augmented OAS response accompanying immune escape for this virus is relatively low. SOIV 2009 offers a rich opportunity for the study of immune escape, because many of the mutation pathways potentially open to this virus are precluded by the continued circulation of H1N1 viruses that re-emerged in 1977. With a relatively low recycling age ( $>62$ years) the number of susceptible people, initially low, is now further reduced. Evolutionary pressure on this virus must be enormous, thus rapid change or extinction should be anticipated.

The mortality rate attributable to influenza was diminished after 1976, but not as a result of vaccination

Over the second half of the 20th century, Canada and the USA had, by far, the lowest influenza-mortality rate, about half that of the highest rate in these countries, which was in the UK. However, a common feature of our graphs (Figure 6; see Additional file 1, Figure S1) is that after $1975 / 6$, only a few mortality peaks anywhere exceeded the mean excess mortality $(C \& S=0)$. Compared with the mean excess mortality in the 25 years before 1980, excess mortality for the period 1980 to 2000 was 40\% lower in Japan, about 20\% lower in Australia and the UK, 10\% lower in France, and 5\% lower in Canada and the USA. Both mortality and variation came to be highest in the UK, among these six countries. There was no discernible trend in influenza-related mortality in four of the six study countries after 1976 (Canada, France, the UK. and the USA). In Australia, mortality rate models of $\mathrm{H} 3$ seasons after 1976 differed significantly, showing mortality reduction in all age groups, but proportionately less in the older elderly population. Only in Japan, where curiously, the elderly population was not vaccinated at all, was there evidence of mortality reduction favoring the older elderly population. For the peak mortality years (all H3 seasons), the oldest elderly population in all countries had the highest relative mortality (Figure 6, dashed lines). By contrast, in type $\mathrm{B}$ and $\mathrm{A}(\mathrm{H} 1 \mathrm{~N} 1)$-dominated seasons (the troughs), the oldest elderly population tended to have either the lowest relative mortality, or had values that were little different from those of younger people. These observations are remarkable because programs for influenza vaccination principally targeting the elderly population were instituted in all of these countries except for Japan, and these programs dramatically increased in coverage after 1980. In Japan, influenza vaccination targeted only children in a program that was begun in 1972 and that terminated in 1987 [55]. None of the elderly population received any vaccine, and no influenza vaccine was deployed in Japan during the period 1993 to 1996/97, after which a more conventional vaccination program including elderly people was deployed.

Could influenza vaccine be more effective in B-dominated and H1N1-dominated seasons than in those dominated by $\mathrm{H} 3$ viruses? This would run counter to the conventional wisdom that inactivated influenza vaccines induce lower rates of seroprotection against $\mathrm{B}$ viruses than against either $\mathrm{H} 3 \mathrm{~N} 2$ or $\mathrm{H} 1 \mathrm{~N} 1$ viruses [56]. The lethality of $\mathrm{H} 3$ viruses and the benign nature of Btype and H1N1 viruses for the elderly person is possibly better explained by the relatively low mutation rate of B-type influenza viruses and greater historical experience with viruses similar to the $\mathrm{H} 1$ viruses. In any case, it is clear that the pattern of influenza-attributable mortality, including the overall decline, has been unaffected, at the population level, by the distribution of influenza vaccine.

If there is no evidence that excess mortality has declined in the older elderly population, who have been subject to the greatest increase in and the most comprehensive coverage with influenza vaccination; if the only decrease in excess mortality among the older elderly occurred in the one country that did not vaccinate its elderly population; and if an argument can be made that conventional, inactivated virus vaccines may even engender a defect in viral clearance, then the trial design for vaccines should be re-examined. One of several potential issues these observations raise is the use of placebo controls. The well-characterized lack of efficacy in the elderly population [57-59] suggests that ethical concerns about placebo use may be misplaced. Detection of vaccine effects is intrinsically difficult. Detection of such effects in a population with little expected effect requires large samples and control of all anticipated confounders. We suggest that investigation of influenza vaccines in elderly populations might be best performed using as many such controls as possible. Additionally, if recent progress in understanding the immunology of the dengue virus has a valid analogy or indeed any application to influenza, then the immune escape of AARPs is potentially fraught with particular peril, because pandemic viruses are often highly immunodominant, whereas subsequent variants are less so. It is likely that new forms of influenza vaccine [60] and possibly new modes of administration may be needed to protect those elderly people who were initially immune, from the effects of exposure to variants of emergent viruses at and after immune escape. 


\section{Additional material}

Additional file 1: Exposition of Methods and Models. Details of techniques used are presented, together with formal proofs of the claimed properties of the method for estimating excess mortality. This file also includes a rainbow coloration version of the text Figure 6 to permit the reader to estimate the actual data used.

Additional file 2: XS mortality rates fitted to an exponential model. This Microsoft Excel file contains estimates for the coefficients of an exponential fit to every season for which data were available for each of the six countries studied.

\section{Abbreviations}

AARP: Above the age of recycling persons; AC: All-cause (used for both mortality due to all causes and excess mortality due to all causes); ACxsMR: All-cause excess mortality rate; B-type: Influenza subtype B; C\&S: Centering and scaling; H1, H1N1: Influenza subtype $A(H 1 N 1) ; H 2, H 2 N 2$ : influenza

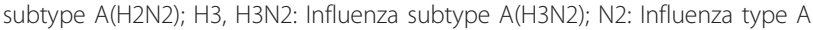
(neuraminidase type 2); OAS: Original antigenic sin.

\section{Acknowledgements}

Access to literature search and copies for TR was provided by the Boston Medical Library. This study was supported, in part, by the Multinational Influenza Seasonal Mortality Study (MISMS) effort within the Fogarty International Center and the US NIH (to GC), and by the American Lebanese-Syrian Associated Charities (ALSAC) (to JMCC). Funding for the conversion of the Japanese all-cause mortality data to machine-readable form was provided by a special grant from the Entropy Research Institute.

\section{Author details}

${ }^{1}$ Entropy Research Institute, 345 S. Great Road, Lincoln, 01773, Massachusetts, USA. ${ }^{2}$ Mathematical, Computational and Modeling Sciences Center, School of Human Evolution and Social Change, Arizona State University, Tempe, 85287, Arizona, USA. ${ }^{3}$ Division of Epidemiology and Population Studies, Fogarty International Center, National Institutes of Health, 31 Center Dr-MSC 2220, Bethesda, 20892-2220, Maryland, USA. ${ }^{4}$ Department of Infectious Diseases, St. Jude Children's Research Hospital, 262 Danny Thomas Place, Memphis, 38104, Tennessee, USA. ${ }^{5}$ Department of Pediatrics, University of Tennessee Health Sciences Center, 50 N. Dunlap, Memphis, 38104, Tennessee, USA.

\section{Authors' contributions}

TR acquired the data, performed excess mortality calculations, prepared draft plots of Figures 1, 2, 3, 4, 5, 6, 7 and Additional file 1, Table S1, and drafted the manuscript. GC provided key references and insight, developed the universal attack rate model, performed the analysis of the exponential model of excess mortality, generated drafts and revisions of Figure 8 , and prepared final versions of all figures. JAM provided continuous feedback, was chiefly responsible for the integration of molecular genetic and genomic data, and identified viral evolutionary events likely to be responsible for immune escape. All three authors contributed to the design and form of the manuscript, reviewed and commented upon all drafts, and have read and approved the manuscript for publication.

\section{Competing interests}

TR reports receiving about $\$ 5,000$ in 2010 for services provided to Novartis, Inc. in the review of influenza vaccine clinical trials. The material of this paper was developed subsequent to his work with Novartis. Neither Novartis nor any other body exerted any influence upon the authors with regard to the data or the interpretation thereof used in this paper, and no one except the authors and Drs D.S. Fedson, W.P. Glezen, and A-J Valleron (esteemed colleagues and former co-authors) have reviewed the contents. Apart from the above, there are no potential conflicts of interest known to any of the authors.

\section{References}

1. Thompson WW, Shay DK, Weintraub E, Brammer L, Cox N, Anderson LJ, Fukuda K: Mortality associated with influenza and respiratory syncytial virus in the United States. JAMA 2003, 289:179-186.

2. Simonsen L, Reichert TA, Viboud C, Blackwelder WC, Taylor RJ, Miller MA: Impact of influenza vaccination on seasonal mortality in the US elderly population. Arch Int Med 2005, 165:265-72.

3. Scholtissek C: Genetic reassortment of human influenza viruses in nature. In Textbook of Influenza. Edited by: Nicholson KG, Webster RG, Hay AJ. Oxford: Blackwell Science; 1998:, Chap 11.

4. Smith GJD, Bahl J, Vijaykrishna D, Zhang J, Poon LLM, Chen H, Webster RG, Peiris JSM, Guan Y: Dating the emergence of pandemic influenza viruses. PNAS 2009, 106:11709-12.

5. McCullers JA, Saito T, Iverson AR: Multiple genotypes of influenza B virus circulated between 1979 and 2003. J Virol 2004, 78:12817-28.

6. Rambaut A, Pybus OG, Nelson MI, Viboud C, Taubenberger JK, Holmes EC: The genomic and epidemiological dynamics of human influenza $A$ virus. Nature 2008, 453:615-9.

7. Nelson MI, Viboud C, Simonsen L, Bennett RT, Griesemer SB, St. George K, Taylor J, Spiro DJ, Sengamalay NA, Ghedin E, Taubengerger JK, Holmes EC: Multiple reassortment events in the evolutionary history of $\mathrm{H} 1 \mathrm{~N} 1$ influenza A virus since 1918. PLoS Pathogens 2008, 4:e1000012.

8. Miller MA, Viboud C, Balinska M, Simonsen L: The signature features of influenza pandemics - Implications for policy. N Engl J Med 2009, 360:2596-8.

9. Simonsen L, Clarke MJ, Schonberger LB, Arden NH, Cox NJ, Fukuda K: Pandemic versus epidemic influenza mortality: a pattern of changing age distribution. J Inf Dis 1998, 178:53-60.

10. Reichert T, Chowell G, Nishiura H, Christensen RA, McCullers JA: Does glycosylation as a modifier of original antigenic sin explain the case age distribution and unusual toxicity in pandemic novel H1N1 influenza? BMC Infect Dis 2010, 10:5.

11. Chowell G, Bertozzi SM, Colchero MA, Lopez-Gantell HL, Alpuche-Aranda C, Hernandez M, Miller MAl: Severe respiratory disease concurrent with the circulation of H1N1 influenza. N Engl J Med 2009, 361:674-9.

12. Vaillant L, La Ruche G, Tarantola A, Barboza P: Epidemiology of fatal cases associated with pandemic H1N1 influenza 2009. Euro Surveill 2009, 14:19309.

13. Jacobs JH, Archer BN, Baker MG, Cowling BJ, Heffernan RT, Mercer G, Uez O, Hanshaoworakul W, Viboud C, Schwartz J, Tchetgen E, Lipsitch M: Searching for sharp drops in the incidence of pandemic A/H1N1 influenza by single year of age. PLoS One 2012, 7:e42328.

14. Scholtissek C, Von Hoyningen V, Ron R: Genetic relatedness between the new 1977 epidemic strains (H1N1) of influenza and human influenza strains isolated between 1947 and 1957 (H1N1). Virology 1978, 89:613-7.

15. Ahmed R, Oldstone MBA, Palese P: Protective immunity and susceptibility to infectious diseases: lessons from the 1918 influenza pandemic. Nature Immunol 2007, 8:1188-93.

16. , Australia: ABS Cause of Death, Australia (cat 3303.0) Unpublished data available on request. Canada: Special tabulation, Canadian mortality database, Statistics Canada, Ottawa, Ontario, (2003). France: Data from the 'Centre d'epidemiologie sur les causes medicales de deces'; the access url is: [http://www.cepidc.vesinet.inserm.fr/cgi-bin/broker.exe]. Japan: Vital Statistics of Japan: Deaths by sex and age, month of occurrence and year of birth. These paper files were provided by Dr M Onishi of Becton Dickinson \& Co and were extracted for electronic usage by Applied Microlmage Corporation, Waltham MA: UK: All-cause, disease specific monthly mortality and population data were provided by Dr Alex Elliot of the Birmingham Research Unit of the Royal College of General Practitioners. US: National Center for Health Statistics. Vital Statistics of the United States, 'Mortality', public use files, 1959-1999.

17. Reichert TA, Simonsen L, Sharma A, Pardo SA, Fedson DS, Miller MA Influenza and the winter increase in mortality in the United States, 1959-99. Am J Epidemiol 2004, 160:492-502.

18. Neter J, Wasserman W: Applied linear statistical models Boston, MA: Richard D. Irwin, Inc: 1974

19. Brundage JF: Cases and deaths during influenza pandemics in the United States. Am J Prev Med 2006, 31:252-56.

20. PRISMA:[http://www.prisma-statement.org/]. 
21. Mossong J, Hens N, Jit M, Beutels P, Auranen K, Mikolajczyk R, Massari M, Salmaso S, Scalia Tomba G, Wallinga J, Heijne J, Sadkowska-Todys M, Rosinska M, Edmunds WJ: Social contacts and mixing patterns relevant to the spread of infectious diseases. PLoS Med 2008, 5:381-91.

22. Britten $\mathrm{RH}$ : The incidence of epidemic influenza, 1918-19. Pub Health Rep 1932, 47:303-39.

23. P Hardelid P, N Andrews N, K Hoschler K, Stanford E, Baguelin M Waight PA, Zambon M, Miller E: Assessment of baseline age-specific antibody prevalence and incidence of infection to novel influenza AH1N1 2009. Health Technol Assess 2010, 14:115-92.

24. Davis LE, Caldwell GG, Lynch RE, Bailey RE, Chin TDY: Hong Kong influenza: The epidemiological features of a high school family study analyzed and compared with a similar study during the 1957 Asian influenza epidemic. Am J Epidemiol 1970, 92:240-7.

25. Shoenbaum SC, Coleman MT, Dowdle WR, Mostow SR: Epidemology of influenza in the elderly: evidence of virus recycling. Am J Epdemiol 1976, 103:166-73.

26. Kim U, Baumler A, Carruthers C, Bielat K: Immunological escape mechanism in spontaneously metastasizing mammary tumors. PNAS 1975, 72:1012-6.

27. Klenerman P, Zinkernagel RM: Original antigenic sin impairs cytotoxic $T$ lymphocyte responses to viruses bearing variant epitopes. Nature 1998, 394:482-5.

28. Sharrar RG: National influenza experience in the USA, 1968-69. Bull WId Hith Org 1969, 41:361-6.

29. Viboud C, Grais RF, Lafont BA, Miller MA, Simonsen L: Multinational Influenza Seasonal Mortality Study Group. Multinational impact of the 1968 Hong Kong influenza pandemic: evidence for a smoldering pandemic. J Infect Dis 2005, 192(2):233-48, Epub 2005 Jun 15.

30. Reichert T, Christensen RA: It's not about smoldering or neuraminidase There were two variants of the $\mathrm{A}(\mathrm{H} 3 \mathrm{~N} 2)$ pandemic virus differing in internal genes. J Inf Dis 2005, 192:1858-60.

31. Kendal AP, Minuse E, Maassab HF, Hennessy AV, Davenport FM: Influenza neuraminidase antibody patterns of man. Am J Epidemiol 1973, 98:96-103.

32. Fedson DS, Huber MA, Kasel JA, Webster RG: Presence of A/Equi-2 hemagglutinin and neuraminidase antibodies in man. Proc Soc Exp Biol Med 1972, 139:825-6.

33. Ilyushina NA, Rudneva IA, Shilov AA, Klenk HD, Kaverin NV: Postreassortment changes in a model system: HA-NA adjustment in an H3N2 avian-human reassortant influenza virus. Arch Virol 2005, 150:1327-38.

34. Lindstrom SE, Cox NJ, Klimov A: Genetic analysis of human H2N2 and early H3N2 influenza viruses, 1957-1972: evidence for genetic divergence and multiple reassortment events. Virology 2004, 328:101-19.

35. Masurel N: Serological characteristics of a 'New' serotype of influenza A Virus: the Hong Kong strain. Bull WId Hith Org 1969, 41:461-8.

36. Clarke SKR, Heath RB, Sutton RNP, Stuart-Harris CH: Serological studies with Asian strain of influenza A. Lancet 1958, 1:814-8.

37. Olson DR, Simonsen L, Edelson PJ, Morse SS: Epidemiological evidence of an early wave of the 1918 influenza pandemic in New York City. Proc Natl Acad Sci USA 2005, 102:11059-63.

38. Andreasen V, Viboud C, Simonsen L: Epidemiologic characterization of the 1918 influenza pandemic summer wave in Copenhagen: implications for pandemic control strategies. J Infect Dis 2008, 197:270-8.

39. Chowell G, Viboud C, Simonsen L, Miller MA, Acuna-Soto R: Mortality patterns associated with the 1918 influenza pandemic in Mexico: evidence for a spring herald wave and lack of preexisting immunity in older populations. J Infect Dis 2010, 202:567-75.

40. Chowell G, Viboud C, Simonsen L, Miller MA, Acuna-Soto R, Díaz JM, Martínez-Martín AF: The 1918-19 influenza pandemic in Boyacá, Colombia. Emerg Infect Dis 2012, 18(1):48-56, doi: 10.3201/eid1801.101969.

41. Dowdle WR: Influenza A virus recycling revisited. Bull WId HIth Org 1999, 77:820-8.

42. Lessler J, Riley S, Read JM, Wang S, Zhu H, Smith GJD, Guan Y, Qiang Jiang C, Cummings DAT: Evidence for antigenic seniority in Influenza A (H3N2) antibody responses in southern China. PLoS Pathogens 2012, 8: e1002802.

43. Zinkernagel RM, Hengartner H: Protective 'immunity' by pre-existent neutralizing antibody titers and preactivated $\mathrm{T}$ cells but not by so-called 'immunological memory'. Immunol Rev 2006, 211:310-9.
44. Kalia V, Sarkar S, Gourley TS, Rouse BT, Ahmed R: Differentiation of memory B and T cells. Curr Opin Immunol 2006, 18:255-64.

45. Francis T Jr: On the doctrine of original antigenic sin. Proc Am Phil Soc 1960, 104:572-8.

46. Powers DC, Belshe RB: Vaccine-induced antibodies to heterologous influenza A H1N1 viruses: effects of aging and 'original antigenic sin'. J Inf Dis 1994, 169:1125-9.

47. Saglanmak N, Andreasen V, Simonsen L, Molbak K, Miller MA, Viboud C: Gradual changes in the age distribution of excess deaths in the years following the 1918 influenza pandemic in Copenhagen: using epidemiological evidence to detect antigenic drift. Vaccine 2011, 29(Suppl 2):B42-48.

48. The influenza epidemic of 1926: A preliminary note on certain epidemiological indications. Public Health Reports 1926, 41(No. 34):1759-74

49. Verhoeyen M, Fang R, Jou WM, Devos R, Huylebroeck D, Saman E, Fiers W: Antigenic drift between the haemagglutinin of the Hong Kong influenza strains A/Aichi/2/68 and A/Victoria/3/75. Nature 1980, 286:771-6.

50. Wanzeck K, Boyd KL, McCullers JA: Glycan shielding of the influenza virus hemagglutinin contributes to immunopathology in mice. Am J Respir Crit Care Med 2011, 183:767-73, Epub 2010 Oct 8.

51. Gulati U, Kumari K, Wu W, Keitel WA, Air G: Amount and avidity of serum antibodies against native glycoproteins and denatured virus after repeated influenza whole-virus vaccination. Vaccine 2005, 23:1414-25.

52. Wrammert J, Smith K, Miller J, Langley WA, Kokko K, Larsen C, Zheng NY, Mays I, Garman L, Helms C, James J, Air GM, Capra JD, Ahmed R, Wilson PC: Rapid cloning of high-affinity human monoclonal antibodies against influenza virus. Nature 2008, 453:667-71.

53. Kim JH, Skountzou I, Compans R, Jacob J: Original antigenic sin responses to influenza viruses. J Immunol 2009, 183:3294-3301.

54. Zhou H, Deems MW: Sculpting the immunological response to dengue fever by polytopic vaccination. Vaccine 2006, 24:2451-9.

55. Reichert TA, Sugaya N, Fedson DS, Glezen WP, Simonsen L, Tashiro M: The Japanese experience with vaccinating schoolchildren against influenza. N Eng J Med 2001, 344:889-96.

56. McElhaney, Meneilly GS, Lechelt KE, Beattie BL, Bleackley RC: Antibody response to whole-virus and split-virus influenza vaccines in successful ageing. Vaccine 1993, 11:1055-60.

57. Jefferson T, Rivetti D, Rivetti A, Rudi M, Di Pietrantonj, Demicheli V: Efficacy and effectiveness of influenza vaccines in elderly people: a systematic review. Lancet 2005, DOI:10.1016/S0140-6736(05)67339-4.

58. Goodwin K, Vibud C, Simonsen L: Antibody response to influenza vaccination in the elderly: A quantitative review. Vaccine 2006, 24:1159-69.

59. Simonsen L, Taylor R, Viboud C, Miller MA, Jackson LA: Mortality benefits of influenza vaccination in elderly people: an ongoing controversy. Lancet Infect Dis 2007, 7:658-66.

60. Kim JH, Davis WG, Sambhara S, Jacob J: Strategies to alleviate original antigenic sin responses to influenza viruses. Proc Natl Acad Sci USA 2012, 109:13751-6.

\section{Pre-publication history}

The pre-publication history for this paper can be accessed here: http://www.biomedcentral.com/1741-7015/10/162/prepub

doi:10.1186/1741-7015-10-162

Cite this article as: Reichert et al:: The age distribution of mortality due to influenza: pandemic and peri-pandemic. BMC Medicine 2012 10:162. 